\title{
The human blink reflex
}

\author{
BHAGWAN SHAHANI
}

From the Department of Neurology, The Churchill Hospital, Oxford

SUMMARY A detailed study of the human blink reflex in the different parts of the orbicularis oculi muscle has been carried out. The first component of the blink reflex has been demonstrated in patients with Friedreich's ataxia, who have selective loss of large sensory fibres resulting in loss of proprioceptive input. It has been established that both components of the blink reflex are cutaneous reflexes which represent a highly organized and purposeful mechanism in man. Afferent fibres for the blink reflex have been identified in the human supraorbital nerve and their conduction velocity has been estimated for the first time in man. It has been demonstrated that both components of the blink reflex are mediated by the same group of afferent fibres.

Overend in 1896 first described reflex contraction of the orbicularis oculi muscle to a gentle tap on the forehead. He described it as a new 'cranial reflex' and his careful analysis led him to believe that its motor path was identical with the conjunctival reflex, that the sensory channels lay primarily in the first division of the trigeminal nerve, and that the reflex centre was located in the brain stem. He concluded that this reflex was 'a true skin reflex and not a periosteal reaction'.

After this original description of the blink reflex, facial reflexes were clinically described under a multitude of different names according to the area tapped, the muscles which responded, and the mechanism considered to be responsible. These reflexes were therefore variously classified as periosteal reflex (Bechterew, 1901; Foerster, 1936), skin and periosteal reflex (Guillain, 1920), a perichondreal reflex (Simchowicz, 1922), a bone reflex (Lewendowsky, 1910), and a myotatic or muscle stretch reflex (Weingrow, 1933; Wartenberg, 1945).

Kugelberg in 1952 first described two components in blink reflexes and Rushworth (1962), Bender (1968), and Gandiglio and Fra (1967) have subsequently confirmed Kugelberg's findings. These reflexes recorded electromyographically from the ipsilateral orbicularis oculi muscle were usually elicited by tapping the glabella or stimulating the supraorbital nerve percutaneously. Since 1952 the initial component, which was relatively constant in size and shape and had a brief latency, was considered to be a proprioceptive reflex and the second

'Supported by the Association for the Aid of Crippled Children, New York. Present address: Department of Neurology, Massachusetts General Hospital, Boston, Mass. 02114, U.S.A. component was thought to be a nociceptive reflex evoked by cutaneous stimulation.

During a detailed study of human flexor reflexes 0 in which electrical stimulation of the sole of the foot produced reflex activity in the ipsilateral tibialife anterior muscle, a marked similarity between the two components of the flexor reflex and the blink $\mathbb{D}$ reflex was noted (Shahani and Young, 1968 Shahani, 1968, 1969). In the light of this experiment evidence, it was suggested that the first componen of the blink reflex, hitherto considered to be $\vec{a}$ proprioceptive reflex, was a cutaneous reflex akin $\stackrel{ }{0}$ to the first component of the flexor reflex. A further detailed study of human blink reflexes has now been carried out in order to determine the exact nature of its two components. In addition the present investigation throws new light on the complex pathways involved in the voluntary and reflex control of the muscles of facial expression.

\section{MATERIAL AND METHODS}

Twenty-eight normal healthy subjects, 16 to 64 years of age, were studied. Six patients with Friedreich's ataxia, 14 to 25 years of age, were also investigated. All $\bar{c}$ understood the nature of the tests and agreed to have them. The subjects lay comfortably supine in a warm room (temperature 75 to $80^{\circ} \mathrm{F}, 24$ to $27^{\circ} \mathrm{C}$ ) and no medication or sedative was used in connection with these studies.

Stimulation, except as noted otherwise, was carried out electrically, and the stimuli were led through an isolation transformer from a DISA Multistim which provided two independent channels of output con- $\mathscr{\sigma}$ tinuously variable from 0 to $50 \mathrm{~V}$, transformer coupled $\mathrm{N}$ with step up ratios of 1,2 , and 5 . Pulse duration could be 
varied from $0.05 \mathrm{msec}$ to $1 \mathrm{msec}$ using the transformer. Beyond $1 \mathrm{msec}$ duration the square wave was appreciably distorted. Supraorbital nerves were stimulated percutaneously using DISA bipolar surface stimulating electrodes. Glabellar tap was performed by tapping the forehead through a rectangular metal plate $2 \times 1.5 \mathrm{~cm}$ attached to a phonograph cartridge which acted as a transducer and triggered the suppressed beam of an oscilloscope. Electromyographic activity was recorded from the inferior half of the orbicularis oculi muscle by means of clip-on electrodes or silver EEG electrodes taped to the skin overlying the muscle. The subjects' eyes were lightly closed at the time of recording. The recording electrodes were connected by a cathode follower input through Tektronix type 122 preamplifiers to a 'Nagard' cathode ray oscilloscope and filmed on $70 \mathrm{~mm}$ unperforated photographic paper.

\section{RESULTS}

Analysis of the pattern of voluntary and reflex activity in the different parts of the muscle orbicularis oculi was first carried out. Figure 1 shows electromyographic activity recorded with clip electrodes from the outer (A), middle (B), and inner (C) parts of this muscle. It was noted that when the subject was asked to wink with one eye he would produce unilateral contraction of the lateral and middle parts of the muscle only (Fig. 1A and B). However, the inner part of the muscle behaved differently so that voluntary activity in this part of the muscle on the ipsilateral side was always accompanied by activity in the inner part of the contralateral muscle (Fig. 1C). Since the inner orbicularis oculi always produced bilateral activity on ipsilateral voluntary contraction, it was decided to record blink reflexes from this part of the muscle to see if these differed in any way from similar responses in other parts of the same muscle. Figure 2 shows blink reflexes recorded from the left (lower trace in each frame) and right (upper trace in each frame) orbicularis oculi. Electrical stimulation was delivered to the left supraorbital nerve. The reflex responses were similar in all parts of the muscle in that the blink reflex was divided into two components on the ipsilateral side and there was a delayed component on the contralateral side. Thus even in the inner part of orbicularis oculi, which could not be voluntarily activated unilaterally, the first component of the blink reflex occurred only on the ipsilateral side.

The minimal latency for the two blink reflex components evoked by electrical stimulation of the supraorbital nerve for 21 normal control subjects is given in Table 1. The latencies of reflex responses elicited by a glabellar tap or electrical stimulation of the skin of the different parts of the face were generally 1 to $2 \mathrm{msec}$ longer. It was noted that the latency of the first component was relatively constant

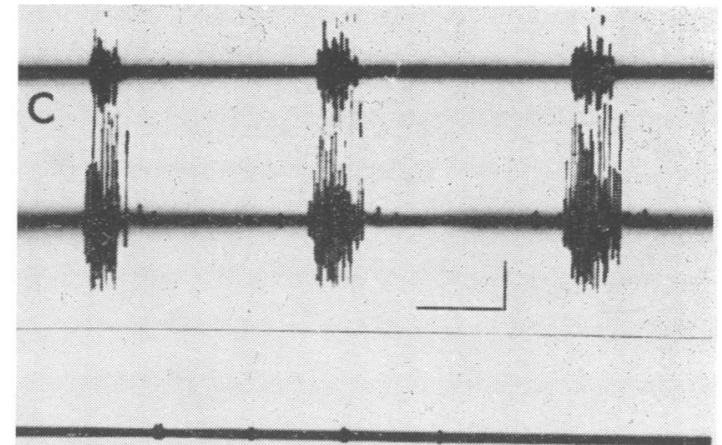

B

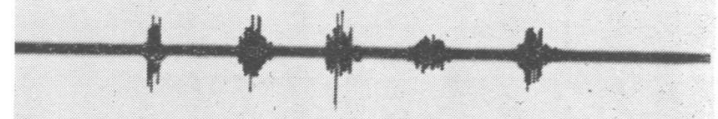

$A$

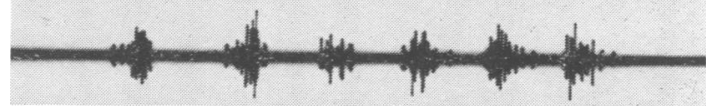

FIG. 1. Normal subject: EMG activity recorded with clip electrodes from the outer (A), middle (B), and inner (C) parts of the left (lower tracing in each frame) and the right (upper tracing in each frame) orbicularis oculi muscle. The electrical activity is produced by voluntary closure of the left eye. Note that the subject is unable to produce unilateral contraction of the inner orbicularis oculi muscle (C). Calibrations are $500 \mathrm{msec}$ (horizontal line) and $300 \mu \mathrm{V}$ (vertical line).

in a given individual; the second showed more variability and difference in the latency of up to $10 \mathrm{msec}$ was sometimes noted. It was difficult to measure latency alterations of the first component when the sweep speed for recording both components of the blink reflex was used. Faster sweep speeds were therefore necessary for accurate latency measurements. Figure 3 shows fluctuation in the latency of the first component. The stimulating electrodes were firmly taped over the supraorbital nerve and electromyographic activity was recorded with clip electrodes. There is a difference of 1.2 (Fig. 3A) and 1.8 (Fig. 3B) msec in the latency of the first component evoked by two successive electrical shocks at an interval of $5 \mathrm{sec}$. Figure 4 shows the latency of a single unit potential, recorded with double coaxial needle electrodes, in the first 
TABLE 1

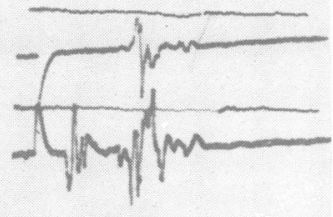

MINIMAL LATENCY AND DURATION OF TWO COMPONENTS OF BLINK REFLEX

\begin{tabular}{llllll}
\hline Subject & \multicolumn{2}{c}{ Latency $(\mathrm{msec})$} & & \multicolumn{2}{c}{ Duration $(\mathrm{msec})$} \\
\cline { 2 - 3 } \cline { 5 - 6 } & $\begin{array}{c}1 \text { Ist } \\
\text { component }\end{array}$ & $\begin{array}{c}2 \text { 2nd } \\
\text { component }\end{array}$ & & $\begin{array}{c}1 \text { st } \\
\text { component }\end{array}$ & $\begin{array}{c}\text { 2nd } \\
\text { component }\end{array}$ \\
\hline
\end{tabular}

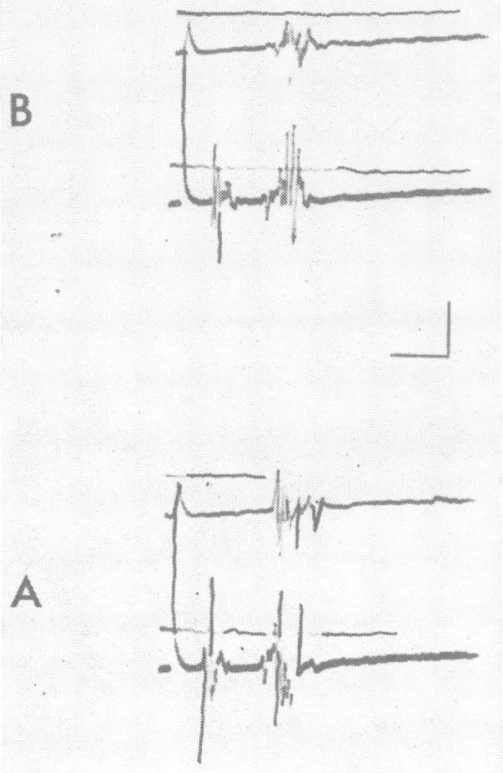

FIG. 2. (Retouched.) Blink reflexes from the left (lower tracing in each frame) and the right (upper tracing in each frame) orbicularis oculi muscle in a normal subject. Electrical stimulus is applied to the left supraorbital nerve. The EMG activity is recorded with clip electrodes from the outer (A), middle (B), and inner part (C) of the lower orbicularis oculi. The calibrations are $20 \mathrm{msec}$ (horizontal line) and $300 \mu V$ (vertical line).

component. The latency for this potential is 18 (Fig. 4A) and $15 \mathrm{msec}$ (Fig. 4B), a difference of 3 msec.

The duration of the first component of the reflex ranged from 8 to $12 \mathrm{msec}$, whereas the second component had a duration of 30 to $40 \mathrm{msec}$. Table 1 shows the duration of the two components of the blink reflex evoked by electrical stimulation of the supraorbital nerve in 21 normal control subjects.

\begin{tabular}{|c|c|c|c|c|c|}
\hline 1 & MR & 12 & 40 & 12 & 38 \\
\hline 2 & BG & 10 & 30 & 10 & 40 \\
\hline 3 & LB & 10 & 28 & 8 & 40 \\
\hline 4 & MB & 14 & 40 & 8 & 30 \\
\hline 5 & IS & 8 & 38 & 10 & 40 \\
\hline 6 & RS & 10 & 40 & 10 & 38 \\
\hline 7 & ME & 12 & 40 & 8 & 36 \\
\hline 8 & BS & 10 & 32 & 12 & 42 \\
\hline 9 & SH & 12 & 34 & 8 & 40 \\
\hline 10 & $\mathbf{A Y}$ & 14 & 40 & 10 & 30 \\
\hline 11 & JT & 12 & 30 & 8 & 32 \\
\hline 12 & JL & 13 & 36 & 10 & 34 \\
\hline 13 & $\mathbf{A M}$ & 12 & 30 & 8 & 34 \\
\hline 14 & WT & 8 & 34 & 10 & 30 \\
\hline 15 & RY & 12 & 30 & 8 & 32 \\
\hline 16 & $\mathrm{CH}$ & 12 & 35 & 8 & 30 \\
\hline 17 & NM & 8 & 36 & 8 & 30 \\
\hline 18 & NW & 8 & 38 & 10 & 32 \\
\hline 19 & WP & 10 & 28 & 10 & 34 \\
\hline 20 & JP & 20 & 30 & 8 & 34 \\
\hline 21 & FH & 10 & 34 & 12 & 30 \\
\hline \multirow{2}{*}{\multicolumn{2}{|c|}{$\begin{array}{c}\text { Mean } \\
\text { SD }\end{array}$}} & $10 \cdot 8$ & $34 \cdot 4$ & $9 \cdot 3$ & $34 \cdot 6$ \\
\hline & & $3 \cdot 2$ & 4.9 & $2 \cdot 3$ & 4.9 \\
\hline
\end{tabular}

Figures 5 and 6 show the effects of low frequency repetitive stimulation on the two components of the blink reflex. The stimuli were delivered to trige supraorbital nerve at the rate of one every 5 and $4 \mathrm{sec}$ (Fig. 5) and 3, 2, and $1 \mathrm{sec}$ (Fig. 6) respectivels It was noted that low frequency stimulation resulted in increased latency and diminution in the amplitude. of the second component (habituation), the delayed component on the contralateral side being most susceptible. At a stimulus frequency of $1 / \mathrm{sec}$, even the first component began to show depression.

For the measurement of conduction velocity in $\frac{\mathbb{Q}}{\mathscr{Q}}$ the afferent pathway of the reflex, the supraorbital $\overrightarrow{\vec{A}}$ nerve was stimulated at a point where it emerges from the supraorbital groove and also high up on the forehead (Fig. 7). Accurate placement of the stimulating electrodes was essential and when this was achieved, single electrical shocks produced a shooting sensation in the distribution of the supraorbital nerve. Supramaximal shocks were delivered via bipolar surface stimulating electrodes with the cathode nearest the orbital groove. Figure 8 의 shows the first reflex responses of the blink reflex evoked by stimulation at the two sites. By measuring the distance between the two sites of stimulation and $\frac{D}{O}$ the difference in the latency of reflex responses evoked from the two sites it was possible to calculate ${ }_{-}^{N}$ the conduction velocity of the afferent fibres mediating the blink reflex (Table 2). 


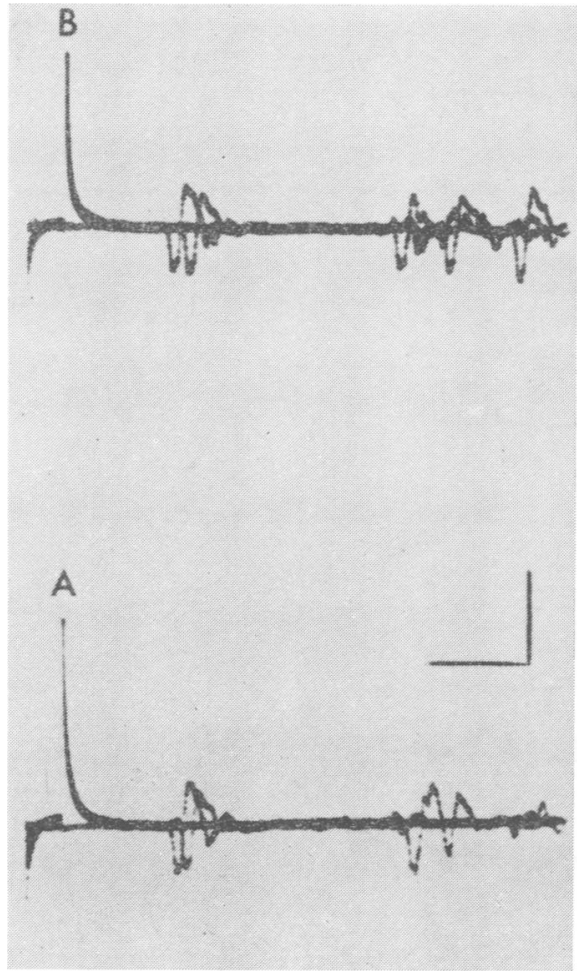

FIG. 3. Blink reflex recorded from the orbicularis oculi muscle in response to a single stimulus to the ipsilateral supraorbital nerve in a normal subject. The EMG activity is recorded with clip electrodes and two traces are superimposed in each frame. Note the fluctuation in the latency of the first component. Calibrations are $10 \mathrm{msec}$ (horizontal line) and $300 \mu \mathrm{V}$ (vertical line).

In most instances the threshold of stimulation for both components of the blink reflex was much the same. To determine if impulses in the same group of sensory fibres produce both components of the blink reflex $5 \mathrm{ml}$. dilute procaine $(1 \%)$ was injected around

TABLE 2

MAXIMAL CONDUCTION VELOCITY IN AFFERENT FIBRES OF HUMAN BLINK REFLEX

\begin{tabular}{cccc}
\hline Subject & $\begin{array}{c}\text { Distance } \\
(\mathrm{cm})\end{array}$ & $\begin{array}{c}\text { Difference in } \\
\text { latency }(\mathrm{msec})\end{array}$ & $\begin{array}{c}\text { Conduction } \\
\text { velocity }(\mathrm{m} / \mathrm{sec})\end{array}$ \\
\hline JP & 6.5 & 2.0 & 32.5 \\
DL & 6.5 & 2.0 & 32.5 \\
NA & 5.5 & 1.5 & 36.6 \\
NM & 5.5 & 1.5 & 36.6 \\
NW & 6.0 & 1.5 & 40.0 \\
WP & 7.0 & 1.75 & 40.0 \\
NS & 5.5 & 1.25 & 44.0 \\
\hline
\end{tabular}

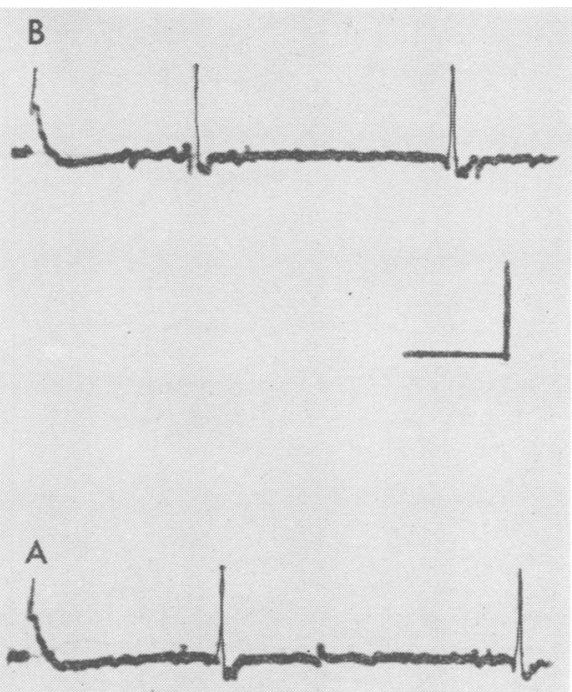

FIG. 4. (Retouched.) Reflexly activated single unit potentials recorded from the orbicularis oculi muscle in response to a single stimulus to the ipsilateral supraorbital nerve in a normal subject. Note the change in the latency of single units recorded in the first blink reflex component. Calibrations are $10 \mathrm{msec}$ (horizontal line) and $300 \mu \mathrm{V}$.

the supraorbital nerve. Sensory modalities of pain (pin prick) and light touch (cotton wool) were tested in the distribution of the supraorbital nerve. When the blink reflex was recorded in Fig. 9B, light touch was well preserved whereas pin prick sensation was blunted. At this time a further $3 \mathrm{ml}$. procaine was injected when even light touch did not feel as normal as on the other side. At this time both components of the blink reflex were diminished in amplitude (Fig. 9C). With further injection of $3 \mathrm{ml}$. procaine, complete anaesthesia in the distribution of the supraorbital nerve was achieved and at this stage no reflexes could be elicited.

The results in patients with Friedreich's ataxia were of special significance. On clinical examination it was impossible to elicit tendon jerks, including the jaw jerk, in any of these patients.

In all patients with Friedreich's ataxia in whom no $H$ waves or median nerve sensory potentials could be obtained, either glabellar tap or electrical stimulation of the supraorbital nerve evoked reflex discharges in the ipsilateral orbicularis oculi muscle with the latency of 10 to $12 \mathrm{msec}$ for the first component and 34 to $40 \mathrm{msec}$ for the second (Fig. 10). The minimal latencies for both components of the blink reflex in these patients are listed in Table 3. It was noted that, although the shape and duration of 
D

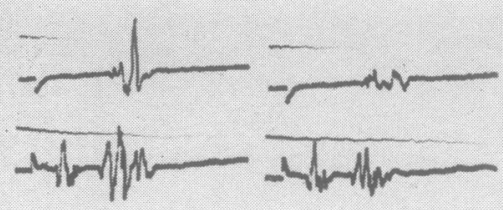

H

C

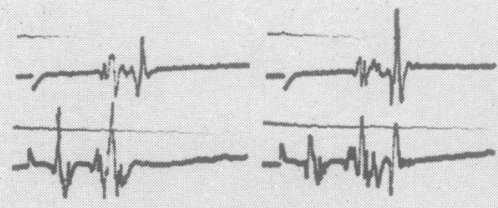

B

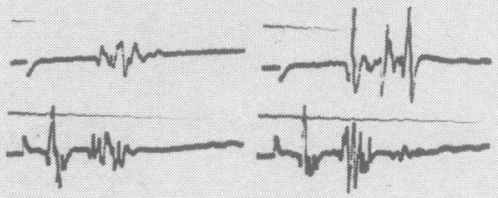

A



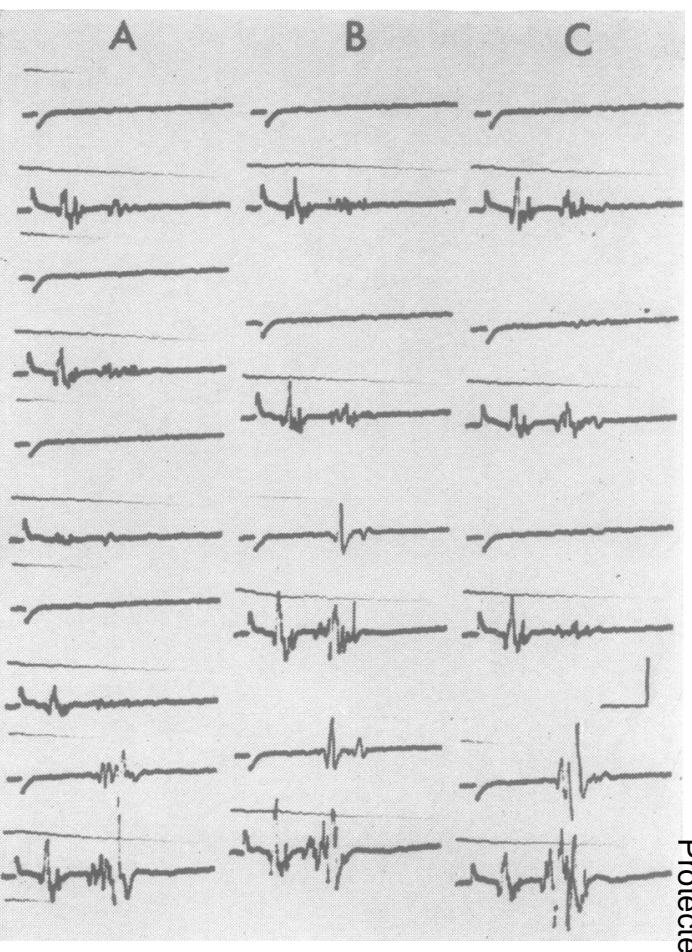

FIG. 6. (Retouched.) Effect of repetitive stimuli (from bottom frame to top frame) at the rate of one every 1 (A), 2 (B) and 3 (C) sec on the two components of the bling reflex. The experimental setting is similar to Fig. 5. The calibrations are $20 \mathrm{msec}$ (horizontal line) and $300 \mu \mathrm{K}$. (vertical line).

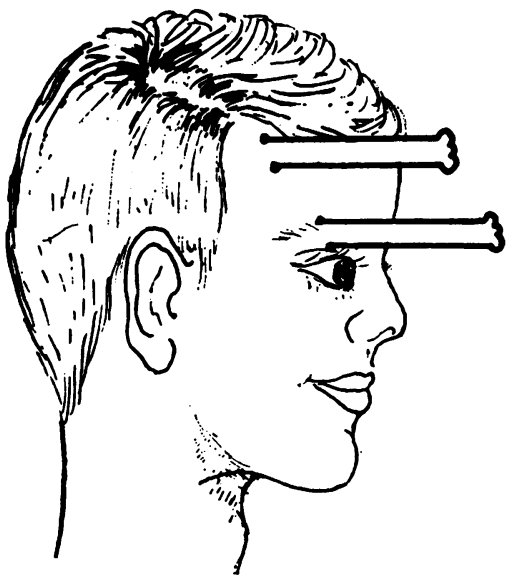

FIG. 7. Two points of stimulation of the supraorbital nerve for the measurement of conduction velocity in the blink reflex afferent fibres. the first component was normal, the second was rather asynchronous and had a duration of more than $50 \mathrm{msec}$ in two patients (Fig. 11).

\section{DISCUSSION}

An electromyographic analysis of the muscle orbicularis oculi has shown the complexity of the pathways which produce voluntary and reflex activity in this muscle. When excited voluntarily, the activity in the innermost part of the lower half of the orbicularis oculi muscle is always accompanied by mirror movement in the contralateral side (Gordon, 1951). However reflex responses in this part of the muscle are not always bilateral, the first component to $\mathrm{D})$ at the rate of one every 4 sec and (from $\mathrm{E}$ to $\mathrm{H}$ ) every sec the two components of the blink reflex in a rve and the EMG activity is recorded from the ipsilateral contralateral orbicularis oculi (upper tracing in the frame). The calibrations are 20 msec (horizontal line) and

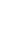



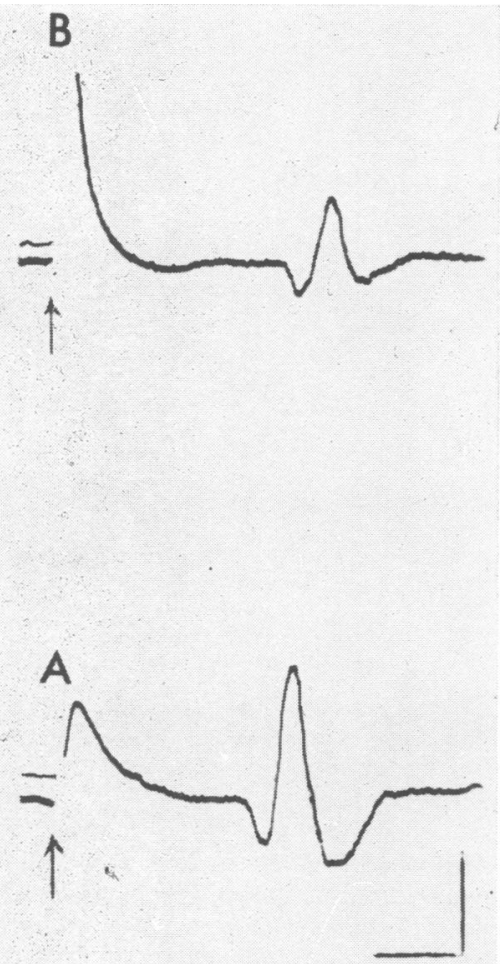

FIG. 8. Blink reflex evoked by electrical stimulation 0 , the supraorbital nerve near the supraorbital groove (A) and high up in the forehead (B). The calibrations are 5 msec (horizontal line) and $300 \mu \mathrm{V}$ (vertical line).

of the blink reflex appearing only on the ipsilateral side. This is an important finding because it shows the highly organized pattern of reflex activity which, by contraction of orbicularis oculi muscle, protects important structures like the bulbus oculi and the retina from external trauma.

The recorded reflex responses in the present study have shown characteristic features of the two components of the blink reflex described by previous authors (Kugelberg, 1952; Rushworth, 1962; Bender, 1967; Gandiglio and Fra, 1967). Both these reflex components, however, can be elicited, not only by a glabellar tap or stimulation of supraorbital nerve but also by cutaneous electrical stimulation over a very wide area of the face (Shahani and Young, 1968; Shahani, 1968, 1969). The generally accepted view that the first component of the blink reflex is a proprioceptive or a myotatic reflex is therefore open to question.

One of the reasons put forward in support of the
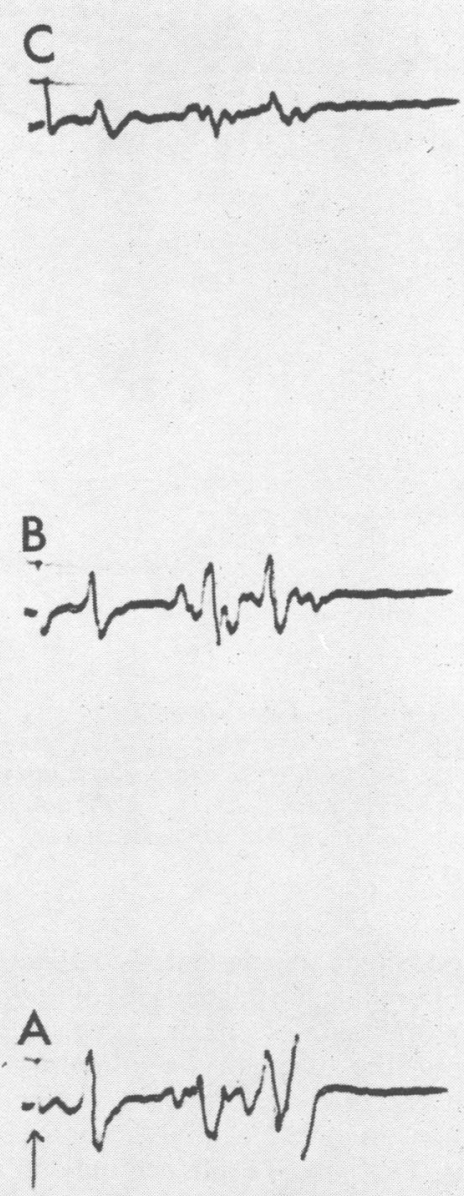

FIG. 9. (Retouched.) Effect of injection of dilute procaine around the supraorbital nerve on the two components of the blink reflex. The blink reflex recorded before (A) and after the injection around the supraorbital nerve (B) (pin prick blunted with preservation of light touch) and with further injection of dilute procaine $(\mathrm{C})$, when even the light touch does not feel normal. Calibrations are $20 \mathrm{msec}$ (horizontal line) and $300 \mu \mathrm{V}$ (vertical line).

hypothesis that the first component is a proprioceptive reflex was its relatively constant latency (Kugelberg, 1952) fixed within $\pm 0.5 \mathrm{msec}$ (Rushworth, 1962). However in the present study it has been demonstrated that there may be a difference of up to $1.8 \mathrm{msec}$ in the latency of this component. 


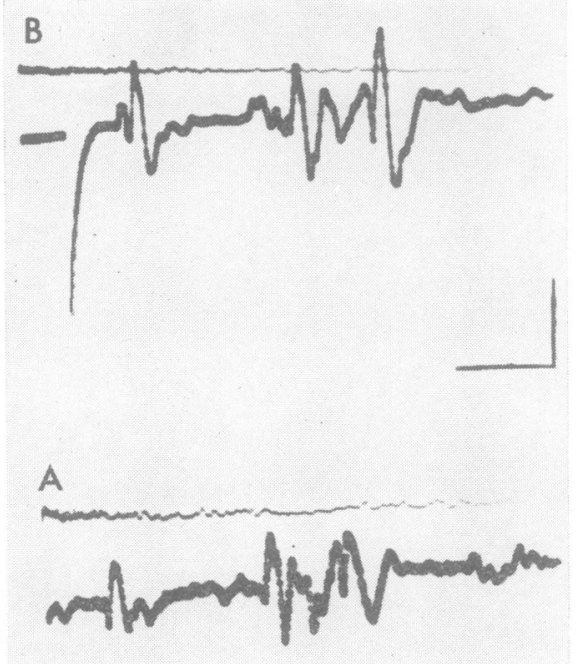

FIG. 10. (Retouched.) Two components of the blink reflex produced by a glabellar tap (A) and electrical stimulation of the ipsilateral supraorbital nerve (B) in a patient with Friedreich's ataxia. Calibrations are 20 msec (horizontal line) and $200 \mu \mathrm{V}$ (vertical line).

Furthermore, single unit potentials activated in this component have latency fluctuations of up to $3 \mathrm{msec}$. Since the stimulating electrodes were fixed in one position and the strength of stimulus was not altered, differences in the conduction velocity of the afferent fibres involved cannot account for these fluctuations. This can be explained only on the basis of differences in the central delay and is further evidence against the first reflex component being a proprioceptive monosynaptic reflex mediated by the fastest conducting afferent fibres.

The conduction velocity of the afferent fibres

TABLE 3

LATENCY AND DURATION OF TWO COMPONENTS OF BLINK REFLEX IN FRIEDREICH'S ATAXIA

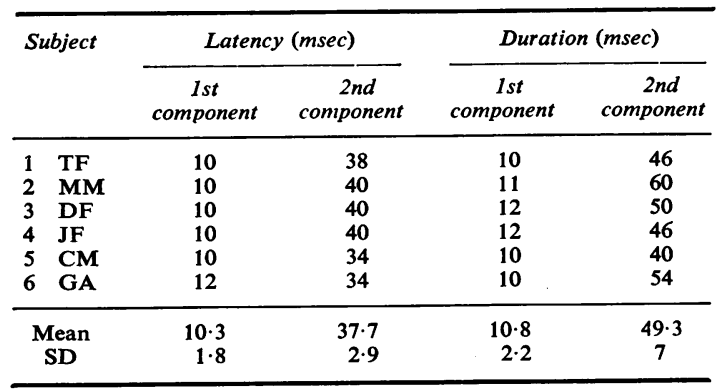
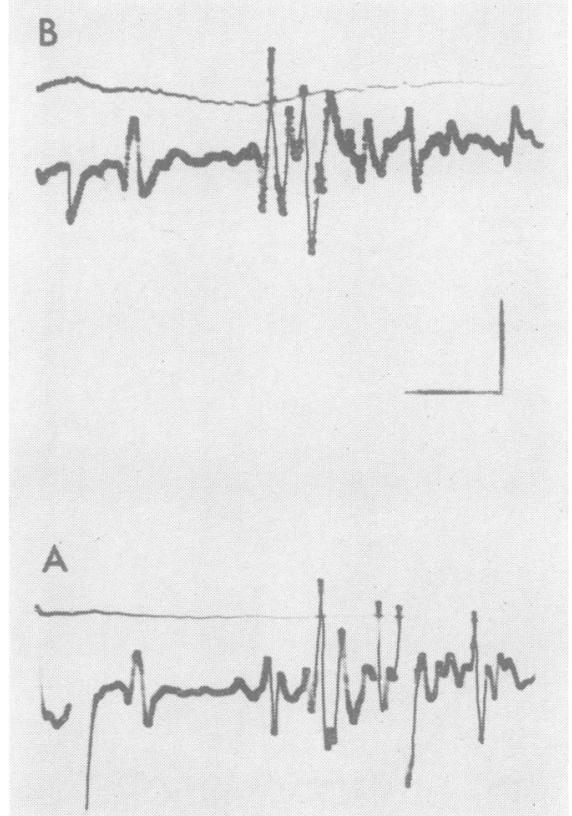

FIG. 11. (Retouched.) Blink reflexes recorded from two patients with Friedreich's ataxia, in response to stimulation of the ipsilateral supraorbital nerve. Note the preservation of both components with prolongation of the second component of the blink reflex. Calibrations are $20 \mathrm{msec}$ (horizontal line) and $200 \mu V$ (vertical line).

mediating the blink reflex in man has been found to range from 32.5 to $44 \mathrm{msec}$. Darian-Smith (1966) identified four fibre groups in the supraorbital nerve of the cat with mean conduction velocities of 67,35 , 23 , and $12 \mathrm{msec}$. If the human supraorbital nerve were to contain similar sized sensory fibres, it would seem that the blink reflex is not mediated by the fastest conducting fibres but by medium sized fibres conducting in the range of $35 \mathrm{~m} / \mathrm{sec}$.

Since both reflex components behaved in a similar fashion at different stages of anaesthetic block with dilute procaine, it would seem that both components are mediated by the same group of fibres. Furthermore both components of the blink reflex are well preserved at a time when sensory fibres mediating sensation of pain are blocked. The experiments of Matthews and Rushworth (1957a, b) in cats have shown that dilute procaine can preferentially block small-sized fibres. Whether or not this can be achieved in human experiments, where the peripheral nerves are not usually exposed, is debatable at the present time (Gassel and Diamontapolous, 1965). It cannot be stated categorically, therefore, what size 
of fibres were blocked at different stages of anaesthetic block. Kugelberg (1952) has suggested that receptors for light touch or pain are not adequate for eliciting the first reflex component and experimental evidence presented here tends to support his impression.

It has been reported previously that low frequency repetitive stimulation results in habituation of the second component of the blink reflex whereas the first component shows little or no change (Kugelberg, 1952; Rushworth, 1962; Gandiglio and Fra, 1967). This difference in the pattern of response led previous authors to believe that the first reflex component is a monosynaptic reflex. However, in a recent study it has been shown that reflexes which have relatively longer central delay show more tendency to habituation compared with those which have a shorter central delay (Shahani, 1969). The finding that the delayed component on the contralateral side, which must have a relatively longer pathway because the fibres have to cross to the opposite side, is the first to be extinguished in repetitive stimulation supports this hypothesis. It is therefore unnecessary to postulate monosynaptic pathways for the first reflex component on the basis of response to repetitive stimulation.

The electrophysiological studies carried out in the present investigation have confirmed the histopathological findings (Hughes, Brownell, and Hewer, 1968) that there is loss of large sensory fibres in Friedreich's ataxia. Examining a series of patients with heredofamilial disorders, Dyck and Lambert (1968) were unable to record sensory potentials in patients with Friedreich's ataxia and the present investigation has confirmed their finding. In addition, no $\mathbf{H}$ reflex could be recorded from the gastrocnemius-soleus muscle. Magladery and McDougal (1950) demonstrated that the afferent fibres mediating the $\mathrm{H}$ reflex consist of the fastest conducting fibres belonging to group Ia. The absence of the $H$ reflex and the tendon jerk therefore indicate loss of large sensory fibres from the muscle spindles. Preservation of the first components of the blink reflex in these patients, therefore, suggests that it is unlikely to be a proprioceptive reflex.

The normal values for the minimal latency of both reflex components in Friedreich's ataxia suggest that afferent fibres mediating this reflex are mediumsized fibres, which are spared in this disorder. The conduction velocity of $32 \cdot 5-44 \mathrm{~m} / \mathrm{sec}$ of blink reflex afferent fibre in normal control subjects is in keeping with this conclusion.

As reported previously (Shahani and Young, 1968), it is of some interest to note that, while they have been reported in masseter, extraocular muscles, and the tongue (Cooper and Daniel, 1963), typical muscle spindles have not been found in facial muscles (Gandiglio and Fra, 1967), though occasional simplified spindles lacking nuclear bags or group Ia fibres have been reported (Bowden and Mahran, 1956; Kadanoff, 1956). The main function of monosynaptic proprioceptive reflexes is to play a part in the subconscious nervous control of muscular contraction, both during movement and during steady contraction under conditions of variable load (Matthews, 1964). Muscles of expression, which are inserted in the facial skin, do not produce movements of the skeleton and therefore are different in function from other skeletal muscles. It would therefore seem unnecessary for the facial muscles to be equipped with the sophisticated mechanisms at the local segmental levels appropriate to muscles organized for posture and locomotion.

One of the most striking features of cutaneous reflexes in man is the adaptation of reflex threshold to its biological function. Thus a light tap or a very small electrical shock on a very wide area of the face is sufficient to evoke a blink reflex. There is no fundamental difference between the two components of the human blink reflex recorded electromyographically from the orbicularis oculi muscle and the two components of the human flexor reflex recorded from the tibialis anterior muscle (Shahani and Young, 1968; Shahani, 1969). The first component of the blink reflex is a manifestation of the complex pathways which are a feature of highly organized cutaneous reflexes in man. The hypothesis that the first blink reflex component is a proprioceptive or myotatic reflex cannot be substantiated either on physiological or anatomical grounds.

I would like to express my grateful appreciation to Professor W. Ritchie Russell for providing excellent facilities for this work and giving his unstinted support, advice, and encouragement. I thank Dr. G. Rushworth for the laboratory facilities and Dr. C. W. M. Whitty for reading the manuscript. I am grateful to Dr. R. L. Hewer for allowing me to see patients with Friedreich's ataxia.

\section{REFERENCES}

Bechterew, W. (1901). Ueber Reflexe im Antlitz-und Kopfgebeite. Neurol. Centralbl., 20, 930-933.

Bender, L. F. (1968). Blink reflex test. Electroenceph. clin. Neurophysiol., 25, 409.

Bowden, R. E. M., and Mahran, Z. Y. (1956). The functional significance of the pattern of innervation of the muscle quadratus labii superioris of the rabbit, cat and rat. J. Anat. (Lond.), 90, 217-227.

Cooper, S., and Daniel, P. M. (1963). Muscle spindles in man; their morphology in the lumbricals and the deep muscles of the neck. Brain, 86, 563-586.

Darian-Smith, I. (1966). Neural mechanisms of facial sensation. In International Review of Neurobiology, pp. 301 - 
395. Edited by C. C. Pfeiffer and J. R. Smythies. Academic Press: New York.

Dyck, P. J., and Lambert, E. H. (1968). Lower motor and primary sensory neuron diseases with peroneal muscular atrophy. II. Neurologic, genetic and electrophysiologic findings in hereditary polyneuropathies. Arch. Neurol. (Chic.), 18, 603-625.

Foerster, O. (1936). In Handbuch der Neurologie. By O. Bumke and O. Foerster. Springer: Berlin.

Gandiglio, G., and Fra, L. (1967). Further observations on facial reflexes. J. neurol. Sci., 5, 273-285.

Gassel, M. M., and Diamantopoulos, E. (1965). The effect of procaine nerve block on neuro-muscular reflex regulation in man. (An appraisal of the role of the fusimotor system.) Brain, 87, 729-742.

Gordon, G. (1951). Observations upon the movements of the eyelids. Brit. J. Ophthal., 35, 339-351.

Guillain, G. (1920). Le réflexe naso-palpébral (réflexe trijumeau-facial) et sa valeur pronostique dans la paralysie faciale. C.R. Soc. Biol. (Paris), 83, 1394-1396.

Hagbarth, K.-E. (1952). Excitatory and inhibitory skin areas for flexor and extensor motoneurones. Acta physiol. Scand., 26, Suppl. 94, 1-58.

Hughes, J. T., Brownell, B., and Hewer, R. L. (1968). The peripheral sensory pathway in Friedreich's ataxia. Brain, 91, 803-818.

Kadanoff, D. (1956). Die sensiblen Nervenendigungen in der mimischen Muskulatur des Menschen. Z. mikr. anat. Forsch., 62, 1-15.

Kugelberg, E. (1952). Facial reflexes. Brain, 75, 385-396.
Lewendowsky, M. (1910). In Handbuch der Neurologie. Edited by $O$. Bumke and O. Foerster. Springer: Berlin.

Magladery, J. W., and McDougal, D. B., Jr. (1950). Electrophysiological studies of nerve and reflex activity in normal man. 1. Identification of certain reflexes in the electromyogram and the conduction velocity of peripheral nerve fibres. Bull. Johns Hopk. Hosp., 85, 265-290.

Matthews, P. B. C. (1964). Muscle spindles and their motor control. Physiol. Rev., 44, 219-288.

Matthews, P. B. C., and Rushworth, G. (1957a). The selective effect of procaine on the stretch reflex and tendon jerk of soleus muscle when applied to its nerve. J. Physiol. (Lond.), 135, 245-262.

Matthews, P. B. C., and Rushworth, G. (1957b). The relative sensitivity of muscle nerve fibres to procaine. J. Physiol. (Lond.), 135, 263-269.

Rushworth, G. (1962). Observations on blink reflexes. $J$. Neurol. Neurosurg. Psychiat., 25, 93-108.

Shahani, B. (1968). Effects of sleep on human reflexes with a double component. J. Neurol. Neurosurg. Psychiat., 31, 574-579.

Shahani, B. (1969). A Study in Human Reflexes. Ph.D. Thesis, Oxford University.

Shahani, B., and Young, R. R. (1968). A note on blink reflexes. J. Physiol. (Lond.), 198, 103P-104P.

Simchowicz, T. (1922). Ueber den Nasenaugenreflex und den Nasenkinnreflex. Dtsch. Z. Nervenheilk., 75, 342-355.

Wartenberg, R. (1945). The Examination of Reflexes: A Simplification. Year Book Publishers: Chicago.

Weingrow, S. M. (1933). Facial reflexes. Arch. Pediat., 50, 234-254. 